\title{
HUBUNGAN OBESITAS DENGAN GAYA HIDUP PADA PASIEN RAWAT JALAN DI BLU RSU Prof. Dr. R.D. KANDOU MANADO
}

\author{
${ }^{1}$ Tuegeh Destyana \\ ${ }^{2}$ Langi Yuanita \\ ${ }^{3}$ Pandelaki Karel \\ ${ }^{1}$ Fakultas Kedokteran Universitas Sam Ratulangi \\ ${ }^{2}$ Bagian Ilmu Penyakit Dalam Fakultas Kedokteran Universitas Sam Ratulangi \\ dg_tuegeh@yahoo.co.id
}

\begin{abstract}
$65 \%$ of the world's population live in countries where overweight. At least 2.8 million adults die each year due to obesity. The prevalence of obesity is associated with urbanization and changes in economic status in developing countries, including in Indonesia. The purpose of this research to determine the relationship between obesity and lifestyle at the Polyclinic of Internal Medicine section/SMF FK-UNSRAT BLU RSU Prof. Dr. R.D Kandou Manado. This research used a cross-sectional study. All outpatients who came in period of November 2012 at the Polyclinic of Internal Medicine section/SMF FK-UNSRAT BLU RSU Prof. Dr. R.D Kandou Manado. There are 58 people who met the inclusion criteria.The result there was no relation of physical activity with obesity. There is a relation of severe meal frequency $>3$ times daily with obesity at $87 \%$ with a $p$ value of 0.004 ( $p<0.005)$. There is a relation with the frequency of eating snacks often with obesity at $70.2 \%$ with $p$ value 0.002 ( $p<0.005)$ found a significant relationship with OR 10.607 times the risk of obesity. There is a relation of not exercising with obesity at $73.2 \%$ with $\mathrm{p}$ value 0.003 ( $\mathrm{p}<0.005$ ) found a significant relationship with OR 6.545 times the risk of obesity. There was no relation of smoking with obesity. As the conclusion the frequency of severe meal > 3 times a day, eating snacks often and not exercising can increase the risk of obesity.
\end{abstract} Keywords: obesity, lifestyle.

\begin{abstract}
Abstrak
Populasi dunia sebesar $65 \%$ di negara dimana kelebihan berat badan. Setidaknya 2.8 juta orang dewasa meninggal setiap tahun akibat obesitas. Prevalensi obesitas ini berhubungan dengan urbanisasi dan perubahan status ekonomi di negara-negara berkembang termasuk di Indonesia. Tujuan penelitian ini untuk mengetahui hubungan antara obesitas dengan gaya hidup pada pasien rawat jalan di Poliklinik Penyakit Dalam BLU RSU Prof. Dr. R.D. Kandou Manado. Metode penelitian menggunakan rancangan potong lintang. Semua pasien rawat jalan yang datang di Poliklinik Penyakit Dalam BLU RSU Prof. Dr. R.D. Kandou Manado periode bulan November 2012. Jumlah sampel 58 orang yang memenuhi kriteria inklusi. Hasilnya tidak terdapat hubungan aktifitas fisik dengan obesitas. Terdapat hubungan frekuensi makan berat $>3$ kali sehari dengan obesitas yakni 87\% dengan nilai p $0.004(\mathrm{p}<0.005)$. Terdapat hubungan
\end{abstract}


hubungan frekuensi makan cemilan sering dengan obesitas yakni $70.2 \%$ dengan nilai $\mathrm{p} 0.002$ (p $<0.005$ ) didapatkan hubungan bermakna dengan OR 10,607 kali berisiko obesitas. Terdapat hubungan tidak berolahraga dengan obesitas yakni 73.2\% dengan nilai $\mathrm{p} 0.003$ ( $\mathrm{p}<0.005$ ) didapatkan hubungan bermakna dengan OR 6,545 kali berisiko obesitas. Tidak ditemukan hubungan riwayat merokok dengan obesitas. Kesimpulan bahwa frekuensi makan berat $>3$ kali sehari, frekuensi makan cemilan yang sering dan tidak berolahraga dapat meningkatkan resiko obesitas.

Kata Kunci : obesitas, gaya hidup.

\section{PENDAHULUAN}

Obesitas atau kegemukan oleh World Health Organization (WHO) di definisikan sebagai akumulasi lemak abnormal atau berlebihan yang dapat menggangu kesehatan. Kegemukan di seluruh dunia telah lebih dari dua kali lipat sejak tahun 1980 dan pada tahun 2008, lebih dari 1.4 miliar yakni orang dewasa kelebihan berat badan. Berdasarkan definisi dari WHO yakni Indeks Massa Tubuh (IMT) untuk wilayah Asia-Pasifik yang lebih besar dari atau sama dengan 25 adalah termasuk dalam kategori obesitas. Populasi dunia sebesar $65 \%$ tinggal di negara dimana kelebihan berat badan dan dibandingkan pria yang lebih dari 200 juta ternyata hampir 300 juta wanita mengalami obesitas. Lebih dari 40 juta anak di bawah usia 5 tahun kelebihan berat badan pada tahun 2010. Setidaknya 2.8 juta orang dewasa meninggal setiap tahun akibat obesitas. Selain itu, 44\% di karenakan oleh diabetes, $23 \%$ penyakit jantung iskemik dan $7 \%$ dan $41 \%$ karena kanker. Secara keseluruhan, lebih dari satu dalam sepuluh dari populasi orang dewasa di dunia mengalami obesitas. ${ }^{1}$

Tampaknya ada berbagai jenis klasifikasi dan cara untuk mendeskripsikan istilah obesitas. Namun yang paling umum, antara lain yang sederhana terjadi akibat asupan kalori yang melebihi kebutuhan atau energi menimbun yang terbagi atas alimentary (pemberian makanan) dan eksogenous (faktor luar). Kemudian ada yang endogeneous akibat gangguan endokrin dan metabolik. Faktor-faktor lain yang ikut berkontribusi terhadap kejadian obesitas adalah faktor sosial, endokrin, fisiologis, genetik, perkembangan, aktivitas dan faktor kerusakan otak. ${ }^{2}$

Indonesia dan negara berkembang lainnya sedang menghadapi transisi epidemiologi, demografi dan urbanisasi. Di bidang gizi telah terjadi perubahan pola makan seperti rendahnya konsumsi buah dan sayur, tingginya konsumsi garam dan meningkatnya konsumsi makanan yang tinggi lemak serta berkurangnya aktivitas berolahraga terutama masyarakat yang tinggal di perkotaan. Perubahan pola makan dan aktivitas fisik ini berakibat semakin banyaknya penduduk yang mengalami masalah gizi lebih berupa obesitas. ${ }^{3}$

Tujuan dilakukan penelitian ini adalah untuk mengetahui hubungan antara obesitas dengan gaya hidup pada pasien rawat jalan di Poliklinik Penyakit Dalam bagian/SMF FK-UNSRAT BLU RSU Prof. Dr. R.D. Kandou Manado. Dengan tujuan khusus untuk mengetahui hubungan obesitas dan 
aktivitas fisik, hubungan obesitas dan perilaku konsumsi, hubungan obesitas dan berolahraga serta hubungan obesitas dan merokok.

\section{METODE PENELITIAN}

Penelitian ini merupakan penelitian observasional analitik dengan rancangan potong lintang. Penelitian ini dilaksanakan di Poliklinik bagian Penyakit Dalam BLU RSU Prof. Dr. R.D. Kandou, Manado. Waktu pelaksanaan penelitian dilakukan pada bulan November 2012.

Populasi adalah semua pasien rawat jalan yang datang di Poliklinik Penyakit Dalam BLU RSU Prof. Dr. R.D. Kandou periode bulan November 2012. Sampel merupakan pasien obese yang datang di Poliklinik bagian Penyakit Dalam BLU RSU Prof. Dr. R.D. Kandou, Manado periode bulan November 2012 yang memunuhi kriteria inklusi. Kriteria inklusi semua pasien rawat jalan yang berdasarkan hasil perhitungan IMT didapatkan nilai $\geq 25$ (kriteria WHO untuk pria dan wanita wilayah Asia-Pasifik). Pasien rawat jalan dengan nilai IMT $\geq 25$ yang bersedia berpartisipasi mengisi kuesioner. Kriteria eksklusi adalah pasien rawat jalan yang dengan penggunaan obatobatan golongan steroid jangka lama, pasien rawat jalan yang mengkonsumsi suplemen penambah atau penurun berat badan, pasien rawat jalan dengan edema dan pasien rawat jalan yang sedang hamil.

Cara penelitian dengan mengukur tinggi dan berat badan kemudian dari hasil perhitungan $\mathrm{IMT}=\left[\mathrm{BB}(\mathrm{kg}) / \mathrm{TB}\left(\mathrm{m}^{2}\right)\right]$ pasien tersebut didapatkan nilainya $\geq 25$ maka pasien akan diminta kesediaannya untuk mengisi kuesioner sebanyak 3 lembar yang telah di persiapkan dan melakukan pendataan variable-variabel yang akan di teliti.
Data kemudian akan diolah dan untuk selanjutnya dianalisis.

\section{HASIL DAN PEMBAHASAN}

Pasien rawat jalan yang datang berobat di Poliklinik bagian Penyakit Dalam BLU RSU Prof. Dr. R.D. Kandou, Manado periode bulan November 2012 berjumlah 1497 orang. Dari hasil penelitian dengan menggunakan kuesioner terhadap 58 pasien yang memenuhi kriteria inklusi dilakukan pengukuran antropometri untuk menilai status IMT dengan berdasarkan kriteria WHO (2002) untuk pria dan wanita wilayah Asia-Pasifik yaitu Kategori bb kurang: < 18.5, kategori normal 18.5-22.9, Kategori bb lebih: $\geq 23$, kategori pra-obese: 23-24.9, kategori obes I: 25-29.9 dan kategori obese II: $\geq 30 .{ }^{4}$ Didapatkan hasil yakni variabelvariabel yang diteliti yang selanjutnya akan dibahas dalam uji analisis bivariat yang dihubungkan dengan risiko obesitas sesuai dengan tujuan khusus penelitian.

Tabel 5.10 Hubungan Aktivitas fisik dengan Obesitas.

\begin{tabular}{|c|c|c|c|}
\hline $\begin{array}{c}\text { AKTIVITAS } \\
\text { FISIK }\end{array}$ & $\begin{array}{r}\text { STA } \\
\text { OBE }\end{array}$ & $\begin{array}{l}\text { TUS } \\
\text { [TAS }\end{array}$ & Total \\
\hline & O.C 1 & O.C 2 & \\
\hline Ringan & 10 & 6 & 16 \\
\hline & $62.5 \%$ & $37.5 \%$ & $100.0 \%$ \\
\hline Sedano & 4 & 11 & 15 \\
\hline seang & $26.7 \%$ & $73.3 \%$ & $100.0 \%$ \\
\hline Berat & 9 & 18 & 27 \\
\hline Beral & $33.3 \%$ & $66.7 \%$ & $100.0 \%$ \\
\hline & 23 & 35 & 58 \\
\hline Total & $39.7 \%$ & $60.3 \%$ & $100.0 \%$ \\
\hline $\begin{array}{l}\text { da tabel diat } \\
\text { tivitas fisik } \\
\text { ngan status t } \\
\text { sil IMT > }\end{array}$ & 5. $\operatorname{Pre}$ & ntase & $\begin{array}{l}\text { nbagian } \\
\text { asarkan } \\
\text { banyak }\end{array}$ \\
\hline
\end{tabular}


didapatkan pada obes 2 (>30) dengan aktivitas fisik berat. Namun pada hasil penelitian ini menunjukkan bahwa tidak ada hubungan yang bermakna.

Penelitian yang dilakukan Humayrah (2009) dengan hasil uji Chi Square menunjukkan bahwa terdapat hubungan nyata antara aktifitas fisik yang berat dan kejadian obesitas pada sampel di Sulawesi Utara yang memiliki peluang 1.469 kali untuk obese. ${ }^{5}$ Menurut Proverawati (2010) seseorang dengan aktivitas fisik yang kurang dapat meningkatkan prevalensi terjadinya obesitas karena orang-orang yang kurang aktif memerlukan kalori dalam jumlah sedikit dibandingkan orang dengan aktivitas tinggi. ${ }^{6}$

Tabel 5.11 Hubungan Frekuensi Makan Berat dengan Obesitas.

\begin{tabular}{rcccc}
\hline & & \multicolumn{3}{c}{ FREKUENSI } \\
& & MAKAN BERAT & Total \\
& & $<3 \mathrm{kali}$ & $>3 \mathrm{kali}$ & \\
\hline & O.C & 3 & 20 & 23 \\
STATUS & 1 & $13.0 \%$ & $87.0 \%$ & $100.0 \%$ \\
OBESITAS & & 5 & 30 & 35 \\
& O.C & 5 & & \\
& 2 & $14.3 \%$ & $85.7 \%$ & $100.0 \%$ \\
\hline \multirow{2}{*}{ Total } & & 8 & 50 & 58 \\
& & $13.8 \%$ & $86.2 \%$ & $100.0 \%$
\end{tabular}

Pada tabel diatas dapat dilihat pembagian frekuensi dalam sehari konsumsi makan berat yaitu < 3 kali sehari dan > 3 kali sehari dengan status tingkatan obese. Hubungan frekuensi makan berat dengan obesitas dari hasil penelitian dengan presentase terbanyak didapatkan pada obese I dengan frekuensi makan berat > 3 kali sehari dengan nilai $\mathrm{p}=0.004(\mathrm{p}<0.05)$ didapatkan hasil yang bermakna dengan menggunakan uji McNemar test meskipun pada penelitian ini terdapat keterbatasan dari kurangnya jumlah sampel.

Hasil penelitian ini didukung juga oleh penelitian yang dilakukan Humayrah (2009) dengan hasil uji Spearman menunjukkan bahwa terdapat hubungan nyata antara frekuensi konsumsi makan berat dan kejadian obesitas pada sampel di Sulawesi Utara. Kecenderungan meningkat akibat konsumsi dari kebiasaan sampel di Sulut yang makan makanan berat dalam jumlah yang besar dan berkali-kali dengan menu makanan yang banyak mengandung lemak hewani. ${ }^{5}$

Menurut Beck (2011) konsumsi lemak yang melampaui kebutuhan tubuh akan energi dapat menimbulkan penimbunan lemak dalam jaringan adipose dan menyebabkan obesitas. $^{7}$

Nathan dan Delahanthy (2010) menyatakan mengkonsumsi makanan dalam porsi besar yang mengandung banyak karbohidrat, maka pankreas harus bekerja keras memproduksi lebih banyak insulin dan kadar gula pun akan meningkat. ${ }^{8}$ 
Tabel 5.12 Hubungan Frekuensi Makan Cemilan dengan Obesitas.

\begin{tabular}{|c|c|c|c|}
\hline \multirow[t]{2}{*}{$\begin{array}{c}\text { FREKUENSI } \\
\text { MAKAN } \\
\text { CEMILAN }\end{array}$} & \multicolumn{2}{|c|}{$\begin{array}{c}\text { STATUS } \\
\text { OBESITAS }\end{array}$} & \multirow[t]{2}{*}{ Total } \\
\hline & O.C 1 & O.C 2 & \\
\hline \multirow{2}{*}{ Jarang } & 9 & $10 \Omega$ & 11 \\
\hline & $81.8 \%$ & $18.2 \%$ & $100.0 \%$ \\
\hline \multirow[t]{2}{*}{ Sering } & 14 & 33 & 47 \\
\hline & $29.8 \%$ & $70.2 \%$ & $100.0 \%$ \\
\hline \multirow{2}{*}{ Total } & 23 & 35 & 58 \\
\hline & $39.7 \%$ & $60.3 \%$ & $100.0 \%$ \\
\hline
\end{tabular}

Pada tabel diatas dapat dilihat frekuensi konsumsi makanan selingan atau cemilan dengan pembagian jarang dan sering. Pada hasil penelitian ini didapatkan hubungan bermakna dengan pengaruh signifikan sekitar 10.607 kali berisiko obesitas pada sampel dengan frekuensi makan cemilan yang sering.

Hubungan frekuensi makan cemilan atau selingan dengan obesitas dari hasil penelitian dengan presentase terbanyak pada obese II dengan frekuensi makan cemilan sering yakni $70.2 \%$ dengan nilai $\mathrm{p}=0.002$ ( $\mathrm{p}<0.05)$ didapatkan hubungan bermakna menggunakan uji Chi-Square dengan OR 10,607 kali berisiko obesitas.

Hasil penelitian ini juga didukung dengan penelitian yang dilakukan oleh Humayrah (2009) dengan hasil uji analisis Spearman menunjukkan berhubungan positif secara nyata dengan $(\mathrm{p}<0.05 ; \quad \mathrm{r}=0.015)$ konsumsi makanan digoreng sebagai jajanan dengan resiko obesitas. ${ }^{5}$

Menurut Proverawati (2010) pola makan makanan cepat saji dapat mempercepat tingkat obesitas. Penelitian membuktikan bahwa orang yang makan di restoran cepat saji secara teratur memiliki perbedaan bermakna antara empat sampai lima kilogram berat badannya dibandingkan orang yang tidak makan makanan cepat saji. $^{6}$

Tabel 5.13 Hubungan Berolahraga dengan Obesitas.

\begin{tabular}{|c|c|c|c|}
\hline \multirow{3}{*}{ BEROLAHRAGA } & \multicolumn{2}{|c|}{ STATUS } & \multirow{3}{*}{ Total } \\
\hline & \multicolumn{2}{|c|}{ OBESITAS } & \\
\hline & $\mathrm{O} . \mathrm{C} 1$ & $\mathrm{O} . \mathrm{C} 2$ & \\
\hline \multirow[t]{2}{*}{$\mathrm{Ya}$} & 12 & 5 & 17 \\
\hline & $70.6 \%$ & $29.4 \%$ & $100.0 \%$ \\
\hline \multirow{2}{*}{ Tidak } & 11 & 30 & 41 \\
\hline & $26.8 \%$ & $73.2 \%$ & $100.0 \%$ \\
\hline \multirow[t]{2}{*}{ Total } & 23 & 35 & 58 \\
\hline & $39.7 \%$ & $60.3 \%$ & $100.0 \%$ \\
\hline
\end{tabular}

Pada tabel diatas dapat dilihat pembagian yang berolahraga dan yang tidak berolahraga dengan status tingkatan obese. Pada hasil penelitian ini didapatkan adanya hubungan bermakna dengan pengaruh signifikan sekitar 6,545 kali lebih berisiko obesitas pada sampel yang tidak berolahraga.

Hubungan berolahraga dengan obesitas dari hasil penelitian dengan presentase terbanyak pada sampel obese II dengan tidak berolahraga yakni $73.2 \%$ dengan nilai $\mathrm{p}=$ 0.003 ( $\mathrm{p}<0.05)$ didapatkan hubungan bermakna dengan OR 6,545 kali berisiko obesitas.

Penelitian ini juga didukung berdasarkan penelitian yang telah dilakukan Humayrah (2009) menunjukkan hubungan yang bermakna dengan risiko obesitas dimana dengan uji Chi Square dimana berhubungan nyata $(\mathrm{p}<0.05)$ dan $(\mathrm{OR}=1.469){ }^{5}$

Menurut WHO (2010) berolahraga merupakan subkategori dari aktivitas fisik yang direncanakan, terstruktur, berulang dan bertujuan dalam arti memperbaiki atau memelihara kebugaran fisik. Aktivitas fisik yang kurang telah diidentifikasi sebagai faktor risiko keempat yang menyebabkan sekitar 3,2 juta kematian secara global 
dimana hal ini merupakan faktor risiko untuk penyakit kronis, dan secara keseluruhan diperkirakan menyebabkan kematian secara global. ${ }^{9}$

Tabel 5.14 Hubungan Merokok dengan Obesitas.

\begin{tabular}{cccc}
\hline \multirow{2}{*}{ MEROKOK } & \multicolumn{3}{c}{ STATUS } \\
& \multicolumn{2}{c}{ OBESITAS } & Total \\
& O.C 1 & O.C 2 & \\
\hline Tidak & 18 & 35 & 53 \\
& $34.0 \%$ & $66.0 \%$ & $100.0 \%$ \\
Ya & 5 & 0 & 5 \\
& $100.0 \%$ & $0.0 \%$ & $100.0 \%$ \\
\hline Total & 23 & 35 & 58 \\
\hline
\end{tabular}

Pada tabel diatas dapat dilihat pembagian sampel yang merokok dan yang tidak merokok dengan status tingkatan obese dimana berdasarkan presentase terbanyak didapatkan pada obese 2 dengan sampel yang tidak merokok. Namun pada hasil penelitian ini menunjukkan bahwa tidak ada hubungan yang bermakna.

Hubungan riwayat merokok dengan obesitas dari hasil penelitian dengan presentase terbanyak pada sampel obese II dengan riwayat tidak pernah merokok yakni $66.0 \%$. Namun pada penelitian ini tidak ditemukan hubungan bermakna.

Menurut penelitian yang dilakukan oleh Humayrah (2009) dengan hasil korelasi Spearman kebiasaan merokok berhubungan negatif dengan nyata $(\mathrm{p}<0.05)$ dengan kegemukan di Sulawesi Utara $(r=-0.067)$. Semakin tinggi kebiasaan merokok semakin rendah kejadian kegemukan. Sampel yang terbiasa merokok berpeluang tidak mengalami obesitas dibandingkan dengan yang tidak terbiasa. ${ }^{5}$

Menurut RISKESDAS tahun 2010 Prevalensi penduduk umur 15 tahun ke atas yang merokok tiap hari secara nasional adalah 28,2 persen. Untuk Sulawesi Utara prevalensinya $29,1 \%$ perokok setiap hari, $7,1 \%$ kadang-kadang, $\quad 10,3 \%$ mantan perokok dan $53,5 \%$ bukan perokok. ${ }^{10}$

Hal ini juga sependapat Ward et al (2001) dalam tinjauan dari 29 studi cross-sectional yang mengevaluasi berat dan status merokok, dimana didapatkan bahwa perokok memiliki berat rata-rata 3-4 kilogram lebih ringan daripada orang yang tidak merokok. ${ }^{11}$

\section{SIMPULAN}

Hasil penelitian menunjukkan bahwa frekuensi makan berat > 3 kali sehari, frekuensi makan cemilan yang sering dan tidak berolahraga dapat meningkatkan resiko obesitas.

\section{DAFTAR PUSTAKA}

1. WHO. Media centre. Fact sheets. Obesity and Overweight. Available at

http://www.who.int/mediacentre/fact sheets/fs311/en/. Accessed on October $13^{\text {th }}, 2012$

2. Timmreck T. Epidemiologi : Suatu Pengantar. Edisi ke-2. Jakarta : EGC; 2005. hal 57

3. Sandjaja dan Sudikno. Prevalensi Gizi Lebih dan Obesitas Penduduk Dewasa di Indonesia. Gizi Indonesia; 2005,31

4. The Asia-Pacific perspective: Redefining obesity and its treatment. WHO Collaborating Centre for the Epidemiology of Diabetes Mellitus and Health Promotion for Noncommunicable Disease. 2000. Melbourne 
5. Humayrah, W. 2009. Faktor Gaya Hidup Dalam Hubungannya Dengan Risiko Kegemukan Orang Dewasa di Provinsi Sulawesi Utara, Gorontalo dan DKI Jakarta. [Skripsi]. Bogor: IPB 2009. Hal. 126-130, 134-138, $142-145$

6. Proverawati A. Obesitas dan Gangguan Perilaku Makan pada Remaja. Yogyakarta : Nuha Medika; 2010. hal: 73,75

7. Beck M. Ilmu Gizi dan Diet. Hubungannya dengan Penyakitpenyakit untuk Perawat dan Dokter. Yogyakarta : ANDI; 2011. hal: 19

8. Nathan D, and Delahanty L. Menerapkan Perubahan Gaya Hidup untuk Mengobati Diabetes dan Penyakit yang Berhubungan dengannya. Dalam : Menaklukkan Diabetes. Jakarta : PT Bhuana Ilmu Populer; 2010. hal: 54

9. WHO. Global Strategy on Diet. Physical Activity and Health. Available at http://www.who.int/dietphysicalactiv ity/pa/en/. Accessed on January $11^{\text {th }}$ 2013

10. [RISKESDAS] Riset Kesehatan Dasar. 2010. Jakarta: Badan Penelitian dan Pengembangan Kesehatan, Departemen Kesehatan, Republik Indonesia

11. Ward KD et al Cessation of Smoking and Body Weight. International Textbook of Obesity, Bjorntorp P (ed.). John Wiley \& Sons, Ltd., Chichester; 2001. hal 323 